RHIC-21

Accelerator Development Department

Brookhaven National Laboratory Associated Universities, Inc. Upton, New York 11973

RHIC Technical Note No. 21

Magnets for RHIC

E. H. Willen

May 1986 


\title{
MAGNETS FOR RHIC
}

\author{
E. H. Willen \\ Brookhaven National Laboratory \\ Upton, N.Y. 11973
}

The Relativistic Heavy Ion Collider (RHIC) is a proposed research facility (1) at Brookhaven National Laboratory for the study of extreme states of matter. By colliding two beams of ions, up to gold in mass and at energies up to $100 \mathrm{GeV} / \mathrm{amu}$, high energy density will be achieved within the nuclei of the colliding ions, leading to a variety of fundamental effects not heretofore observed. The physics to be explored by this Collider is an overlap between the traditional disciplines of nuclear physics and high energy physics. The machine is proposed for construction in the nowempty tunnel built for the former CBA project. In addition to the tunnel, various other facilities needed for the machine are in place, including experimental halls, a beam transfer tunnel from the AGS, and a refrigerator for providing cryogenic helium. Soon to be commissioned is a beam line to carry heavy ions from the BNL Tandem Van de Graaff to the AGS, and a Booster ( $321 \mathrm{MeV} / \mathrm{amu}$ for gold) for the capture and acceleration of the ions prior to injection into the AGS is under construction. Though direct injection into the AGS will be possible, the Booster is necessary to efficiently capture and accelerate the heavier ion species. The AGS will then accelerate the ions (up to 10.7 $\mathrm{GeV} / \mathrm{amu}$ for gold) prior to injection into the

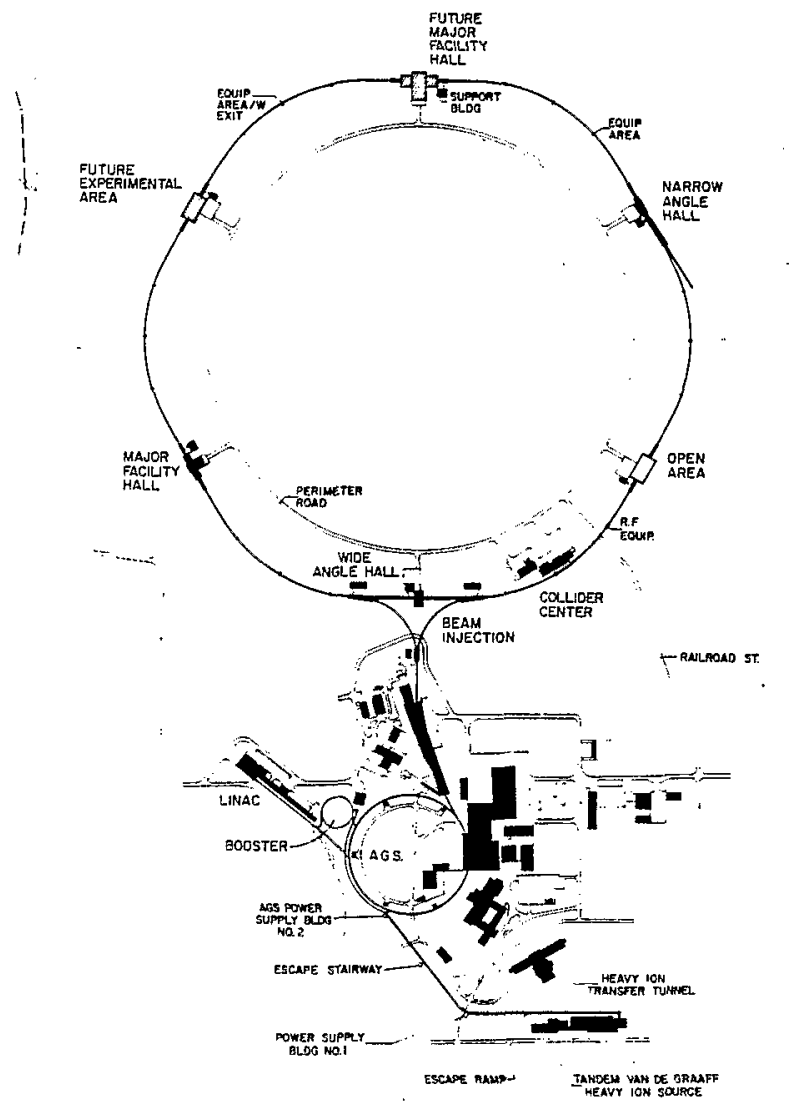

Figure 1. Site Map for RHIC.
Collider. Figure 1 shows the layout of the RHIC project on the laboratory site.

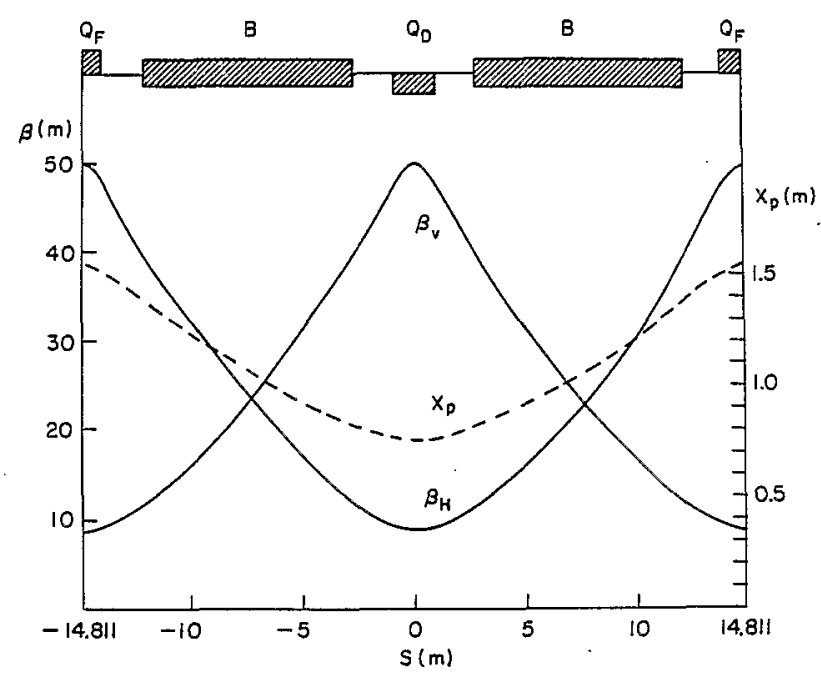

Figure 2. RHIC Regular Arc Cell.

The Collider, including the magnets, is in an advanced state of design. Figure 2 shows the layout of the basic RHIC regular arc cell. Seventy-two such cells are required to complete one ring. The lattice of magnets chosen in the design reflects the need for strong focussing to maintain a small beam size while coping with the severe intrabeam scattering of heavy ion beams. Each cell is $29.622 \mathrm{~m}$ long; it deflects the beam by 77.7 mrad and has a betatron phase advance of $90^{\circ}$.

The layout of the magnets to bring the beams into collision is shown in Fig. 3. Crosing angles from zero to several milliradians are allowed. Because of the need to accomodate both a range of energies and different ion species, from protons to gold, several special large dipole and quadrupole magnets are required near the collision point. Otherwise, the magnets in these intersection regions have characteristics similar to those in the regular arcs.

The characteristics of the dipole and quadrupole magnets required for the arcs and for the intersection regions are given in Table $I$. Table 2 lists the total complement of magnets required in the machine, including the sextupole and multipole correctors located at each of the quadrupole magnets. Current plans are for $10-20 \%$ of these magnets to be built at Brookhaven and the rest to be built in industry over a 4-year construction period. 


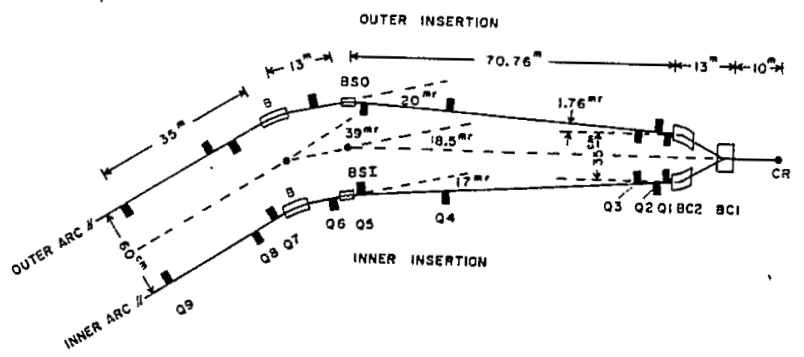

Figure 3. Magnet Layout in the Intersection Regions.

Table 1. Characteristics of the Arc and Intersection Region Dipoles and Quadrupoles for RHIC (100 GeV/anu Operation)

\begin{tabular}{|c|c|c|c|}
\hline Magnet & $\begin{array}{c}\text { Coil ID } \\
\text { (In⿴) }\end{array}$ & $\begin{array}{c}\text { Effective } \\
\text { Length } \\
\text { (m) } \\
\end{array}$ & $\begin{array}{l}\text { Field or } \\
\text { Gradient }\end{array}$ \\
\hline \multicolumn{4}{|l|}{ Arc } \\
\hline dipole & 80 & 9.475 & $3.45 \mathrm{~T}$ \\
\hline quadrupole & 80 & 1.18 & $71.4 \mathrm{~T} / \mathrm{m}$ \\
\hline \multicolumn{4}{|l|}{ Intersection } \\
\hline $\mathrm{BCl}$ & 200 & 3.3 & $4.63 \mathrm{~T}$ \\
\hline $\mathrm{BC} 2$ & 100 & 4.4 & $2.73 \mathrm{~T}$ \\
\hline BS Inner & 80 & 3.57 & $3.45 \mathrm{~T}$ \\
\hline BS Outer & 80 & 5.46 & $3.45 \mathrm{~T}$ \\
\hline B & 80 & 9.46 & $3.45 \mathrm{~T}$ \\
\hline \multicolumn{4}{|l|}{ quadrupoles } \\
\hline$Q 1-Q 3$ & 130 & $1.34-2.21$ & $57.4 \mathrm{~T} / \mathrm{m}$ \\
\hline $04-09$ & 80 & $1.03-1.74$ & $67.4 \mathrm{~T} / \mathrm{m}$ \\
\hline
\end{tabular}

Table 2. RHIC Magnet Inventory

\begin{tabular}{|c|c|}
\hline Regular Arcs & \\
\hline Dipoles & 288 \\
\hline Quadrupoles & 276 \\
\hline Sextupoles & 276 \\
\hline Correctors & 276 \\
\hline Intersection Regions & \\
\hline Standard Aperture Magnets & \\
\hline Dipoles & 48 \\
\hline Quadrupol es Q4-Q9 & 144 \\
\hline Sextupoles $@ Q 9$ & 1.2 \\
\hline Correctors & 144 \\
\hline Large Aperture Magnets & \\
\hline Dipoles (BC1) & 12 \\
\hline Dipoles (BC2) & 24 \\
\hline Quadrupoles $(\mathrm{Q} 1-\mathrm{Q} 3)$ & 72 \\
\hline Correctors & 72 \\
\hline Skew quadrupoles $@ \mathrm{Q} 2$ or $\mathrm{Q} 3$ & 24 \\
\hline Totals & \\
\hline Dipole: & 372 \\
\hline Quadrupoles & 492 \\
\hline Sextupoles & 288 \\
\hline Correctors & 492 \\
\hline Skew quadrupoles & 24 \\
\hline
\end{tabular}

Although there are less dipoles than there are quadrupole and corrector magnets, the arc dipoles nevertheless remain the dominant cost item in the machine. For this reason, the R\&D effort has focussed on this device. Various models have been built, including four in industry, culminating in a half-length model with prototype cross section that was built and tested in the past year.
A cross section of the current dipole coil design is shown in Fig. 4. It has a single layer

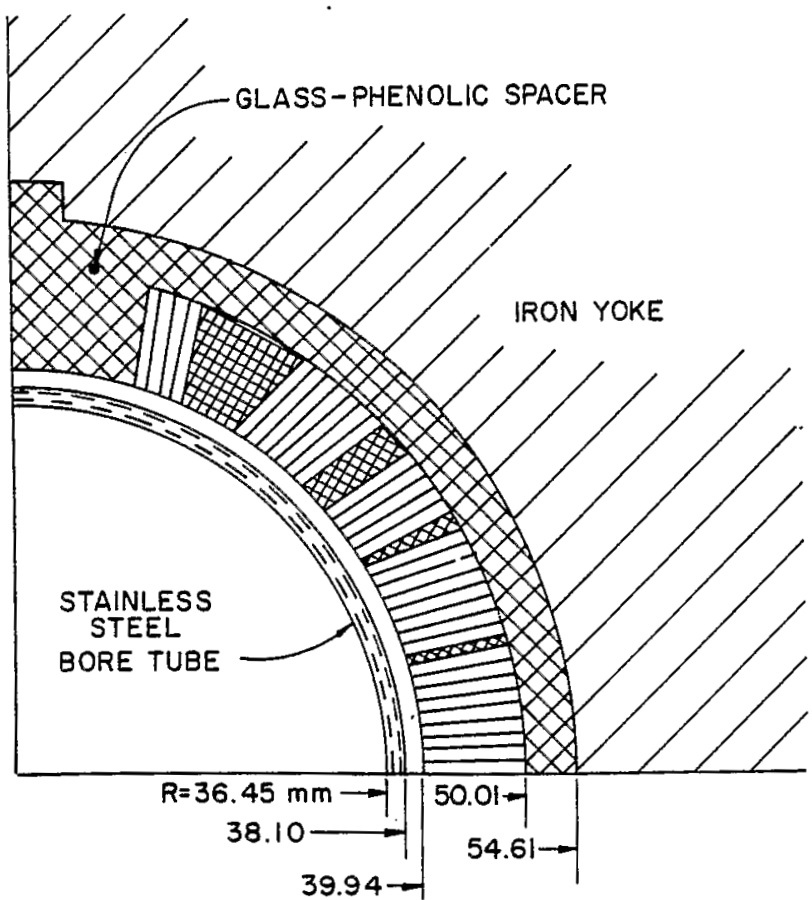

Figure 4. RHIC Dipole Coil Cross Section.

superconducting coil designed to provide the required $3.45 \mathrm{~T}$ bending field for $100 \mathrm{GeV} / \mathrm{amu}$ ions with a generous margin of safety. The superconductor used is the same as that used for the outer coil of the Superconducting Super Collider (SSC) magnet. Figure 5 shows a cross sec-

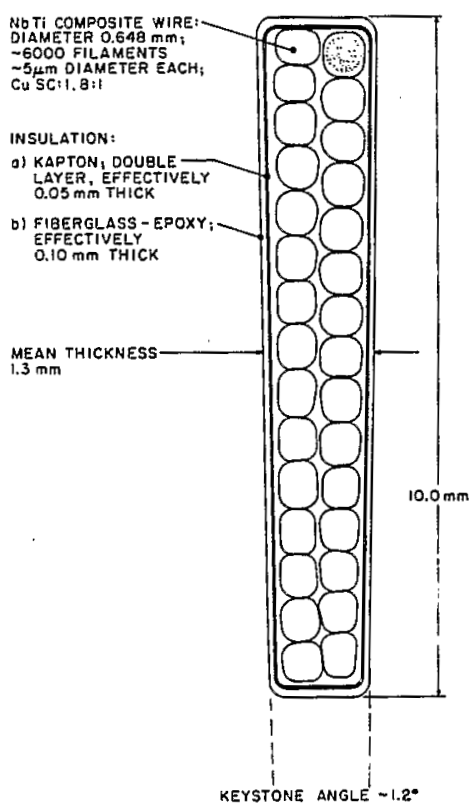

Figure 5. Cross Section of RHIC Superconductor Cable. 
tion of this superconductor in its cabled form. Prestress is applied to the coil directly by the iron yoke through a 5 mm thick insulator-spacer surrounding the coil. The relatively close iron leads to some iron saturation field effects at high field that must be corrected with the lumped corrector magnets located at each quadrupole. . There are no internal trim coils in these magnets, The $10 \mathrm{~m}$ long magnets are assembled in fixtures that introduce the required $47 \mathrm{~mm}$ sagitta during the construction process. The sagitta is locked in place via the outer stainless steel weldment, which also serves as the helium pressure vessel. The cold mass is supported in a cryostat with folded, insulating posts (originally designed by FNAL for the SSC) (2), as shown in Fig. 6. The

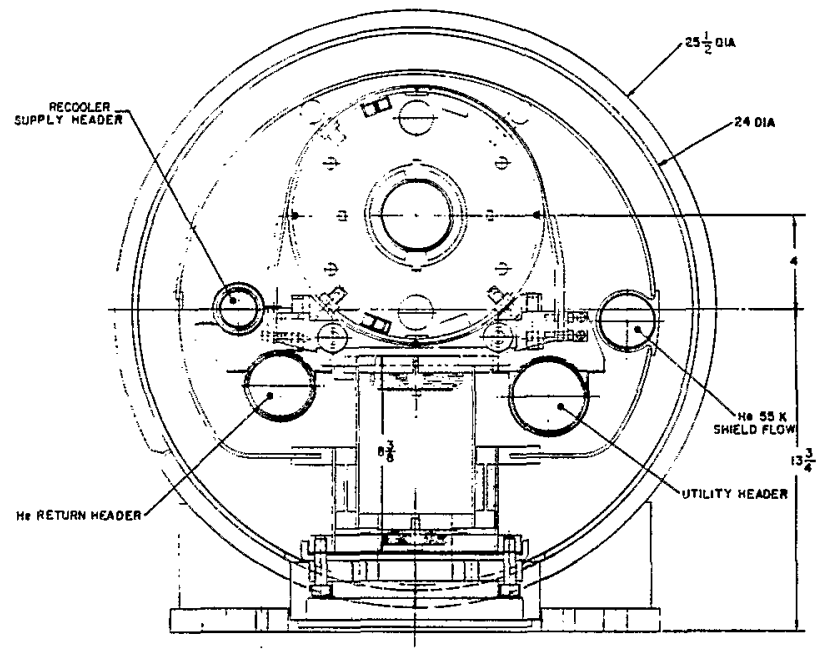

Figure 6. Cross Section of RHIC Dipole in Cryostat.

primary design parameters for the dipole magnet and the superconductor used in its construction are given in Table 3 .

Table 3. Basic Arc Dipole and Superconductor Parameters

\begin{tabular}{|c|c|}
\hline Dipole Para & eters \\
\hline B, minimum operation & $0.24 \mathrm{~T}$ \\
\hline $\mathrm{B}, 100 \mathrm{GeV} / \mathrm{amu}$ & $3.45 \mathrm{~T}$ \\
\hline$B$, quench & $4.6 \mathrm{~T}$ \\
\hline $\begin{array}{l}\text { Current for } 100 \mathrm{GeV} / \mathrm{amu} \\
\text { operation }\end{array}$ & $4.56 \mathrm{kA}$ \\
\hline Inductance & $43 \mathrm{mH}$ \\
\hline $\begin{array}{l}\text { Stored energy at } 100 \mathrm{GeV} / \mathrm{amu} \\
\text { operation }\end{array}$ & $490 \mathrm{~kJ}$ \\
\hline $\begin{array}{l}\text { Length, effective } \\
\text { Sagitta } \\
\text { Coil, number of super- }\end{array}$ & $\begin{array}{l}9.460 \mathrm{~m} \\
47.2 \mathrm{~mm}\end{array}$ \\
\hline conducting turns & 33 \\
\hline $\begin{array}{l}\text { Coil inner radius } \\
\text { Iron outer radius }\end{array}$ & $\begin{array}{l}39.9 \mathrm{~mm} \\
133.3 \mathrm{~mm}\end{array}$ \\
\hline Superconductor Parameters & \\
\hline $\mathrm{Cu} / \mathrm{SC}$ ratio & $1.8: 1$ \\
\hline $\begin{array}{l}\text { Wire diameter } \\
\text { Critical current density }\end{array}$ & $0.648 \mathrm{~mm}$ \\
\hline a $5 \mathrm{~T}, 4.2 \mathrm{~K}$ & $2400 \mathrm{~A} / \mathrm{mm}^{2}$ \\
\hline Number of wires in cable & 30 \\
\hline Width of cable & $9.73 \mathrm{~mm}$ \\
\hline Mid-thickness of cable & $1.16 \mathrm{~mm}$ \\
\hline Keystone angle & $1.2 \mathrm{deg}$. \\
\hline
\end{tabular}

The performance of the half-length model constructed and tested during the past year was excellent. Figure 7 shows the training history of

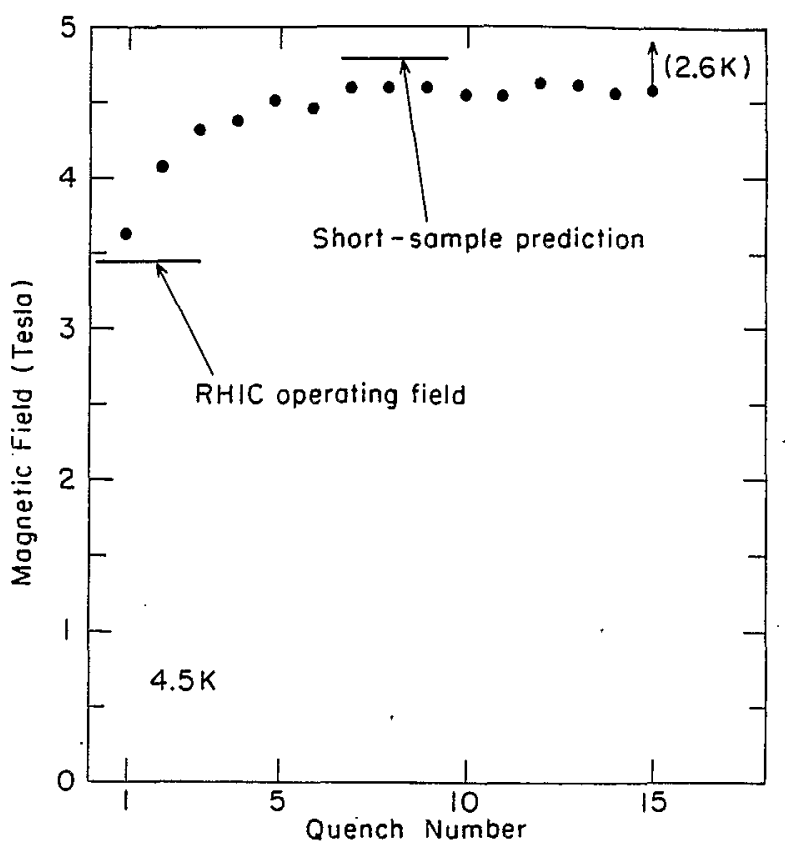

Figure 7. Training History of Prototype RHIC Dipole Magnet.

the magnet. The first quench was above the required operating field and after several additional quenches, the magnet's field reached a level near its short sample limit. It is expected that future magnets will reach a somewhat higher field because of continuing improvements in the current capacity of the superconductor and improved cable fabrication.

The measured transfer function, sextupole harmonic and decapole harmonic are shown in Fig. 8 . The large magnetization evident in the harmonics at low field is due to the large filament size (20 $\mu \mathrm{m}$ ) in the superconductor used for this magnet. Future magnets are expected to benefit from the reduced filament size $(<5 \mu \mathrm{m})$ that is being developed in the very active superconductor R\&D program (3) currently underway. Table 4 lists the measured mean values of the various harmonics, including also the expected mean value and the expected magnet-to-magnet variation extrapolated from CBA experience. It is seen that the harmonics in this prototype are well within the expected error distribution.

The design for the arc quadrupoles is shown in Fig. 9. It too is a single layer magnet using the same conductor as in the dipole. Again the use of copper wedges provides the needed degrees of freedom to achieve good field quality over the aperture of the magnet. The single layer design is particularly welcome in a quadrupole magnet to reduce the number of coils that must be built and assembled. The main parameters for the quadrupole are given in Table 5 . 


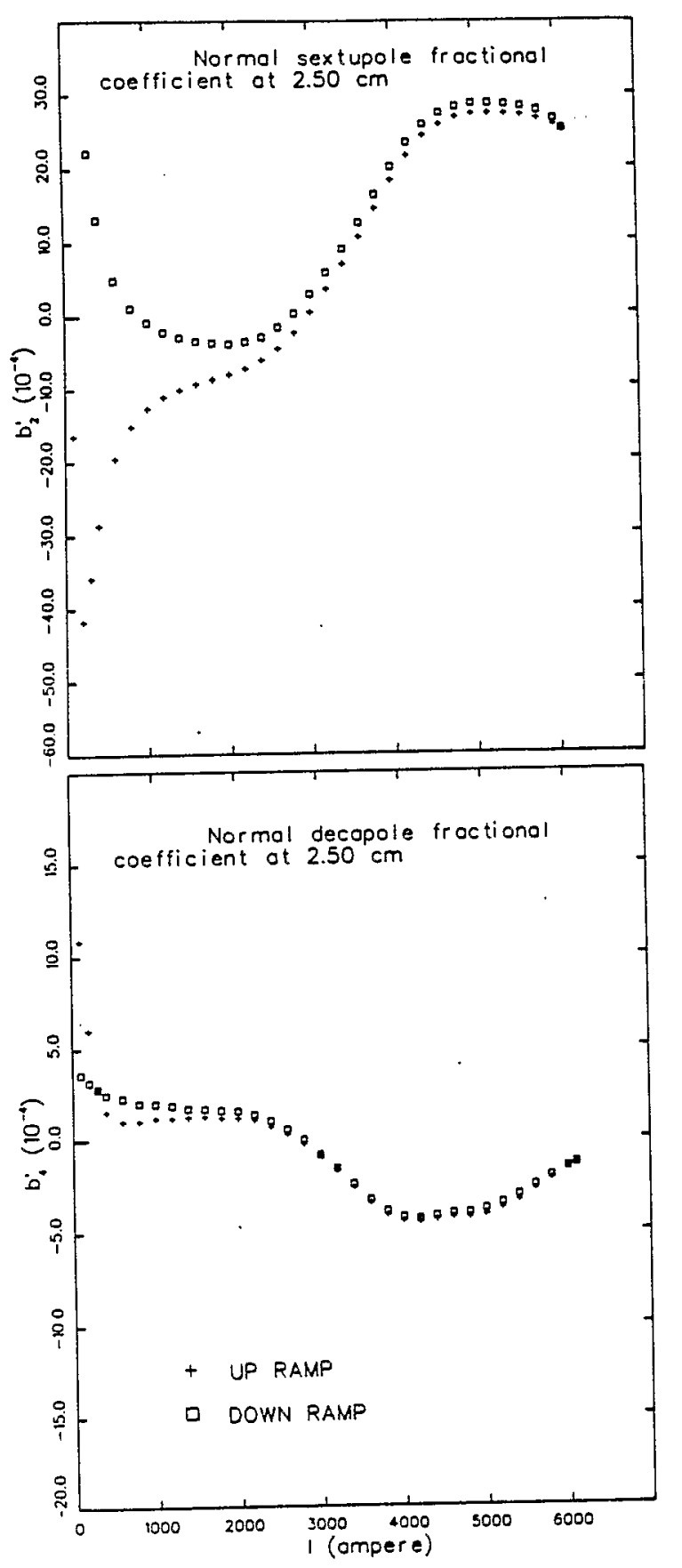

Figure 8. Measured Sextupole and Decapole Harmonics in Prototype RHIC Dipole Magnet.

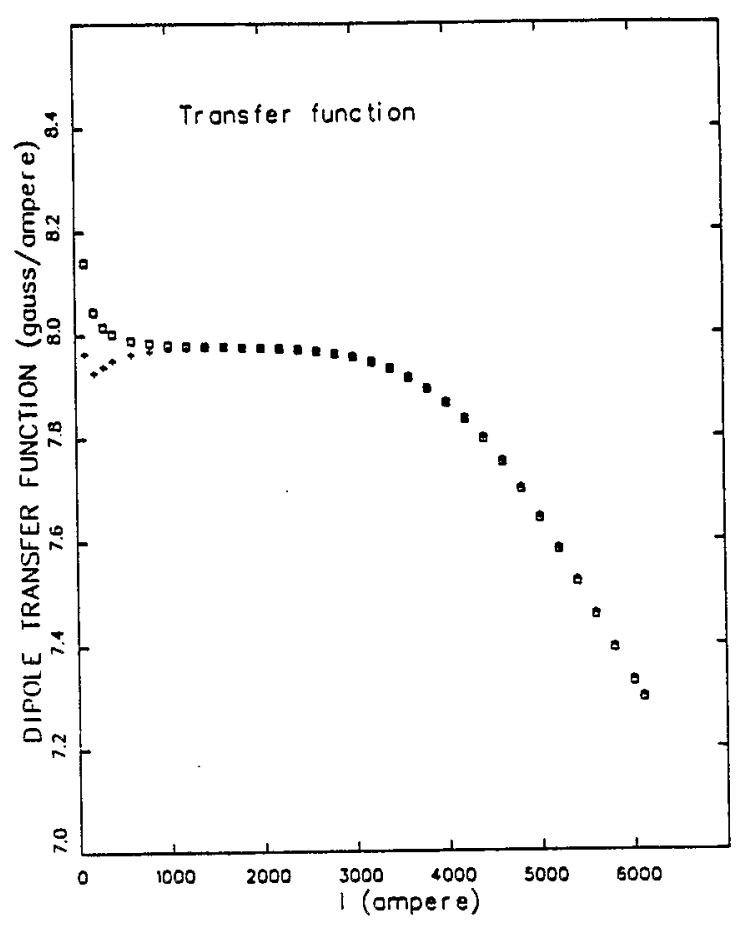

Figure 8 (cont). Measured Transfer Function in Prototype RHIC Dipole Magnet.

Table 4. Harmonics at. $2.5 \mathrm{~cm}\left(\mathrm{x} 10^{-4}\right)$

\begin{tabular}{|c|c|c|c|}
\hline & $\begin{array}{l}\text { Mean, } \\
\text { Measured } \\
1200 \mathrm{~A} \\
\end{array}$ & $\begin{array}{l}\text { Mean, Expected, } \\
\text { Including } \\
\text { Magnetization } \\
\text { for } 20 \mu \mathrm{m} \\
\text { Filaments } \\
\end{array}$ & $\begin{array}{c}\text { Standard } \\
\text { Deviation, } \\
\text { Expected }\end{array}$ \\
\hline $\begin{array}{l}b_{1} \\
b_{2} \\
b_{3} \\
b_{4} \\
b_{5} \\
b_{6} \\
b_{7} \\
b_{8} \\
b_{9}\end{array}$ & $\begin{array}{r}-0.2 \\
-11.2 \\
-0.2 \\
1.1 \\
-0.1 \\
1.1 \\
-0.1 \\
-0.1 \\
0.3\end{array}$ & $\begin{array}{c}- \\
-12 \\
- \\
-2.5 \\
- \\
0.8 \\
- \\
-0.15 \\
-\end{array}$ & $\begin{array}{l}2.1 \\
4.6 \\
1.3 \\
2.2 \\
0.5 \\
0.8 \\
0.2 \\
0.3 \\
0.1\end{array}$ \\
\hline $\begin{array}{l}a_{1} \\
a_{2} \\
a_{3} \\
a_{4} \\
a_{5} \\
a_{6} \\
a_{7} \\
a_{8} \\
a_{9}\end{array}$ & $\begin{array}{r}-3.8 \\
-0.8 \\
-0.3 \\
-0.2 \\
0.5 \\
-0.1 \\
0.2 \\
-0.1 \\
0.3\end{array}$ & $\begin{array}{l}- \\
- \\
- \\
- \\
- \\
- \\
- \\
-\end{array}$ & $\begin{array}{l}4.3 \\
1.3 \\
2.2 \\
0.6 \\
0.9 \\
0.2 \\
0.3 \\
0.1 \\
0.1\end{array}$ \\
\hline
\end{tabular}

Single layer coil magnets are being specified for RHIC because the tunnel exists and the required field to achieve the design goals of the machine $(100 \mathrm{GeV} / \mathrm{amu})$ can be readily obtained in such magnets. In a study performed for the SSC, it was found that single layer magnets are at a 


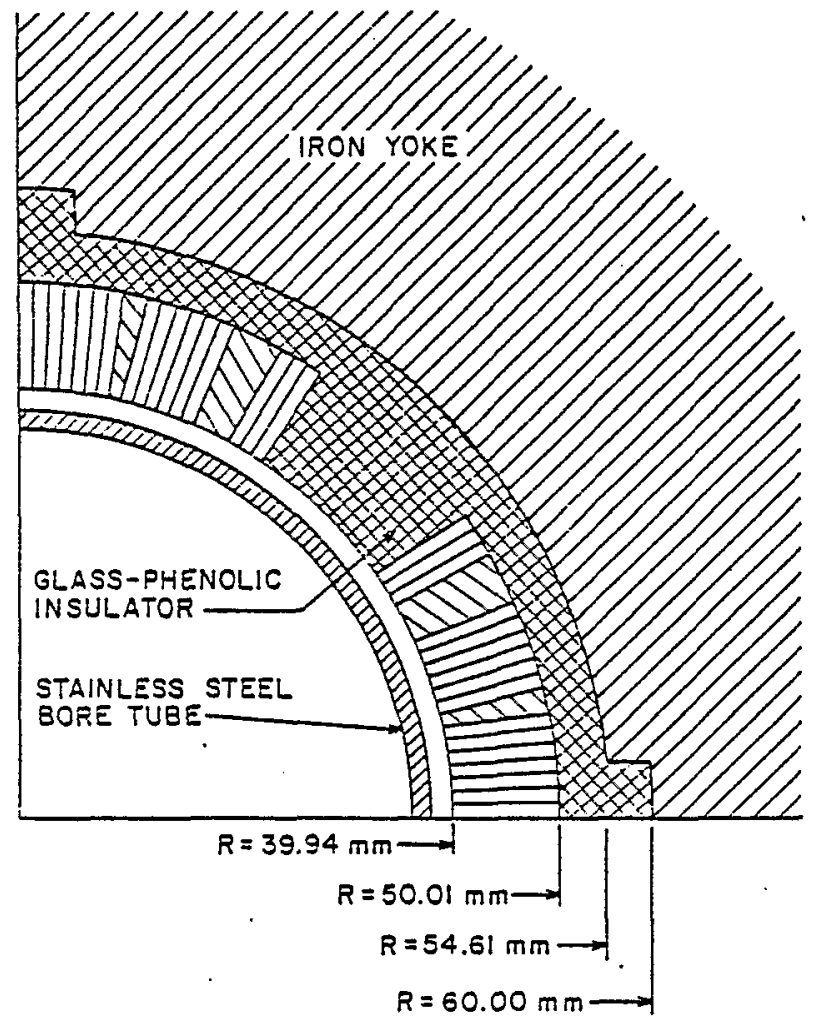

Figure 9. RHIC Quadrupole Cross Section.

Table 5. Basic Arc Quadrupole Parameters

$\bar{G}$, minumum operation (corresponding to $0.24 \mathrm{~T}$ in dipole)

$\mathrm{G}, 100 \mathrm{GeV} / \mathrm{amu}$

$G$, quench

Gurrent for $100 \mathrm{GeV} /$ anu operation $\quad 4.56 \mathrm{kA}$

Inductance

Stored energy at $100 \mathrm{GeV} / \mathrm{amu}$ operation

$3 \mathrm{mH}$

Length, effective

$20 \mathrm{~kJ}$

Coil, number of superconducting turns

$1.24 \mathrm{~m}$

Coil, inner radius

Iron, outer radius

16

$39.9 \mathrm{~mm}$

$133.3 \mathrm{~mm}$

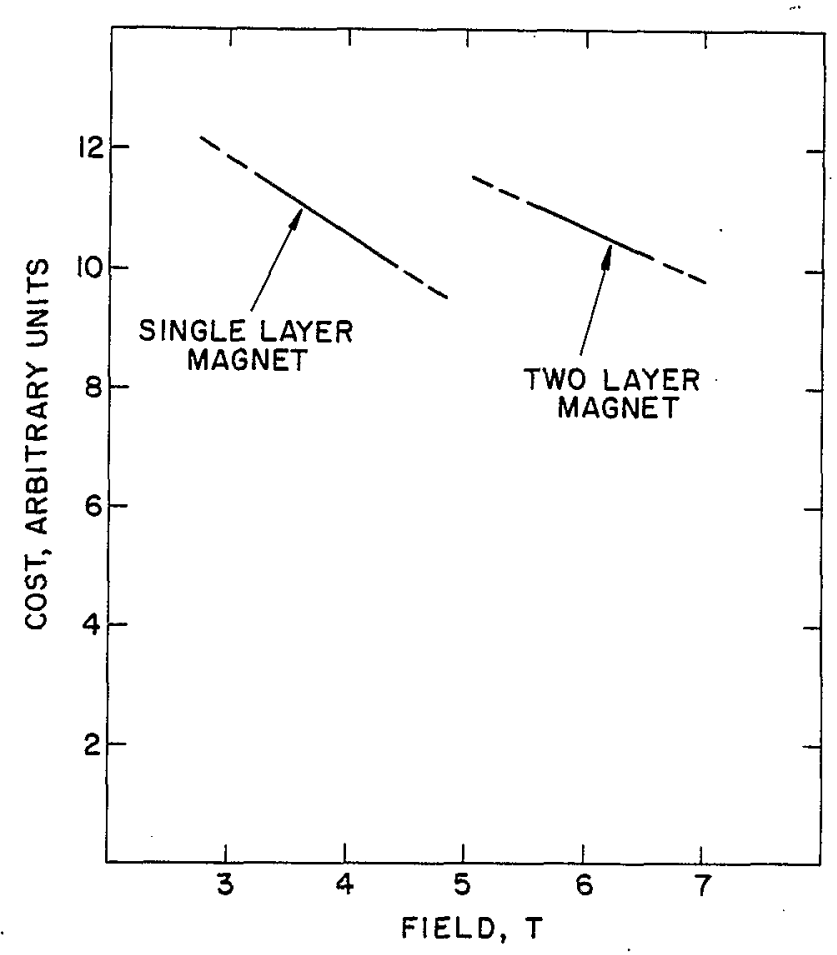

Figure 10. Relative Machine Costs, Including Tunnel, for Single Layer and Two Layer Dipole Magnets.

\section{REFERENCES}

1 Proposal for a Relativistic Heavy Ion Collider, BNL 51932, (March 1986).

2 R.C. Niemann et et a1., "Design, Construction and Performance of a Post Type Cryogenic Support," Adv. Cryo. Engr. 31 (1986) Plenum Press, New York (to be published).

3 A.F. Greene, D.C. Larbalestier, W.B. Sampson, R. Scanlon, BNL SSC Technical Note 39 (June 1985).

cost minimum of total magnet plus tunnel cost. This is illustrated in Fig. 10. The minimum occurs because the superconductor, which dominates the magnet cost, is less efficient in producing field in a two-layer coil design. Thus, the particular requirements of the RHIC machine have fortuitously led to a magnet design that is not only cost advantageous but also highly reliable by virtue of the relative simplicity of a single layer coil magnet.

\section{Acknowledgement}

The work reported here is mostly that of the Magnet Division of the Accelerator Development Department at Brookhaven National Laboratory. The design of the RHIC magnets has been largely carried out by Pat Thompson. 